\title{
Refletindo sobre lobbies alimentares e outras ações corporativas:
}

uma questão de saúde pública

\section{Thinking on food lobbies and other corporate activities:}

a public health issue

Thamillys Rodrigues Souza ${ }^{1}$

Camila Maranha Paes de Carvalho ${ }^{2}$

Foi identificada na última década uma mudança no padrão de consumo alimentar da população brasileira, com substituição de alimentos menos processados pelos ultraprocessados, que contêm alta densidade energética, perfil nutricional desfavorável e que estão associados a comportamentos alimentares nocivos à saúde. Essa nova forma de classificação, proposta por Carlos Monteiro e colaboradores em 2010, se baseia no grau e propósito de processamento dos alimentos e foi pela primeira vez utilizada em uma política pública no Guia Alimentar para a População Brasileira de 2014. Nasce, assim, forte crítica à grande indústria de alimentos ultraprocessados, com o setor produtivo se posicionando, desde o momento de formulação do Guia, contrário a esta classificação. Convergente com este movimento científico-político, diversos autores defendem que, por meio de mecanismos regulatórios, o Estado precisaria lidar com essas corporações, tanto por sua atuação em escala global, quanto por sua capacidade de interferir nos ambientes alimentares - cada vez mais obesogênicos - e, assim, ferir o direito à alimentação adequada e saudável em seu sentido mais amplo. Uma noção promissora a ser utilizada no enfrentamento dessas questões parece ser a dos regimes alimentares, que vêm caminhando em estreita relação com a trajetória da noção de segurança alimentar e nutricional. Desenvolvida por Harriet Friedman e Philip McMichael, essa abordagem visa estabelecer os elos entre a produção e o consumo alimentar e as formas de acumulação próprias aos diferentes períodos do capitalismo desde o fim do século XIX. Nesse sentido, Renato Maluf e Márcio Reis apontam que o segundo regime alimentar deixou como herança um maior distanciamento entre a regulação das atividades em nível nacional e a organização econômica transnacional. Assim, é necessário que novas regras e instituições características de um novo regime alimentar sejam construídas no contexto atual. O presente estudo visa, então, identificar e classificar as ações corporativas da indústria de alimentos frente ao Guia Alimentar para a População Brasileira de acordo com Amy Hillman e Michael Hitt, tendo como possíveis resultados a caracterização das ações corporativas das indústrias alimentícias em relação ao Guia e a identificação de potenciais estratégias contrárias a estas, que visem garantir a manutenção da cultura alimentar do país, respeitando suas características regionais, frente à massificação imposta pelas dietas baseadas em alimentos ultraprocessados. Como potencial contribuição teórica, tal como apontado por Elaine de Azevedo, embora altamente relevante, o tema dos lobbies alimentares e seus impactos à saúde coletiva ainda é pouco pesquisado no Brasil. Assim, torna-se importante um maior a profundamento do tema, bem como dos movimentos contrários e de resistência a essa atuação. 
Palavras-chave: ação corporativa; lobbies alimentares; políticas de alimentação e nutrição; indústria de alimentos.

Keywords: corporate activities; food lobbies; food and nutrition policies; food industry.

1 Bacharel em Jornalismo na Universidade Católica de Pernambuco, graduanda em Nutrição na Universidade Federal Fluminense, bolsista PIBIC/CNPq.

2 Doutora em Saúde Coletiva na Universidade do Estado do Rio de Janeiro. 